\title{
DEFESA DA MORALIDADE CRISTÃ: CANDIDATOS EVANGÉLICOS PARA O LEGISLATIVO PARANAENSE EM 2018
}

\section{Defense of Christian morality: evangelical candidates for the Paranaense Legislative in 2018}

Lucas Alves da Silva ${ }^{1}$ Frank Antônio Mezzomo ${ }^{2}$ Cristina Satiê de Oliveira Pátaro ${ }^{3}$

\begin{abstract}
RESUMO: A presente pesquisa analisa como os candidatos evangélicos à Assembleia Legislativa Estadual do Paraná, em 2018, realizaram suas campanhas eleitorais e publicaram seus materiais no Facebook, promovendo a defesa dos valores cristãos como fonte de moralidade política, a defesa do armamento da população e o combate da legalização das drogas. Percebemos nas últimas décadas o aumento do ativismo religioso na política brasileira, em especial entre os evangélicos, que buscam inscrever seus valores e crenças no cenário público. Para o desenvolvimento dessa pesquisa foram analisados materiais de campanha, tais como jingles, flyers, imagens, vídeos, lives e "santinhos" divulgados na mídia social Facebook dos 45 candidatos evangélicos. As análises realizadas evidenciaram que os discursos em defesa dos valores cristãos foram recorrentes nos materiais, e se mostraram como as principais pautas defendidas pelos candidatos, já o tema do armamento e das drogas não se fizeram presentes com a mesma frequência, mas demonstraram como os candidatos se apropriaram de argumentos religiosos na defesa de tais pautas.
\end{abstract}

Palavras-chave: Moralidade. Armamento. Drogas. Evangélicos. Eleições 2018.

ABSTRACT: The present research analyzes how evangelical candidates to the State Legislative Assembly of Paraná in 2018 carried out their electoral campaigns and published their materials on Facebook, promoting the defense of Christian values as a source of political morality, defending arming the population weaponry, and the fight against the legalization of drugs. In recent decades, we have seen an increase in religious activism in Brazilian politics, especially among evangelicals, who seek to inscribe their values and beliefs in the public arena. For the development of this research, we analyzed campaign materials, such as jingles, flyers, images, videos, lives and election leaflets released on the Facebook social media of the 45 evangelical candidates. The analyzes revealed that the discourses in defense of Christian values were recurrent in the materials and were shown as the main guidelines defended by the candidates. Although the theme of guns and drugs were not present with the same frequency, they nonetheless demonstrated how the candidates have appropriated religious arguments in defense of such guidelines.

Keywords: Morality. Weaponry. Drugs. Evangelicals. Elections 2018.

\footnotetext{
${ }^{1}$ Mestrando do Programa de Pós-Graduação Interdisciplinar Sociedade e Desenvolvimento (PPGSeD) pela Universidade Estadual do Paraná. Bolsista CAPES.

${ }^{2}$ Doutor em História. Professor do Programa de Pós-Graduação Interdisciplinar Sociedade e Desenvolvimento (PPGSeD) da Universidade Estadual do Paraná (Unespar). E-mail: frankmezzomo@ gmail.com

${ }^{3}$ Doutora em Educação. Professora do Programa de Pós-Graduação Interdisciplinar Sociedade e Desenvolvimento (PPGSeD) da Universidade Estadual do Paraná (Unespar). E-mail: crispataro@ gmail.com
} 


\section{Introdução}

Temos observado nas últimas décadas no Brasil a emergência de grupos religiosos no cenário público, em particular na política institucionalizada, de seguimentos cristãos evangélicos, em especial os de vertente pentecostal (IBGE, 2010). Ao adentrar o espaço público, as instituições religiosas têm buscado permear as fronteiras da política, e acabaram por despertar interesse de diversos cientistas sociais, preocupados com as consequências desta imbricação, em particular no que tange ao princípio republicano da laicidade. Neste sentido, o presente texto tem por objetivo analisar como os candidatos evangélicos à Assembleia Legislativa Estadual do Paraná, em 2018, realizaram e publicaram seus materiais de campanhas no Facebook, promovendo a defesa dos valores cristãos como fonte de moralidade política, a defesa do armamento da população e o combate da legalização das drogas. Ressaltamos que, dentre as denominações pertencentes ao grupo evangélico, em nossa análise trataremos das Igrejas pentecostais, em que destacam-se por sua atuação no cenário público as seguintes: Igreja Assembleia de Deus (AD), Igreja Universal do Reino de Deus (IURD), Igreja do Evangelho Quadrangular (IEQ) e Igreja Internacional da Graça de Deus (IIGD).

$\mathrm{O}$ ingresso deste grupo de religiosos na política trouxe à cena pública do país práticas e valores próprios do campo evangélico, que, juntamente com elementos da cultura católica ocultada pela naturalidade de sua presença secular (GIUMBELLI, 2014) -, geram uma disputa tanto por visibilidade como por legitimidade. Desta forma, algumas igrejas têm buscado participar ativamente da formação de uma cultura pública evangélica, em contraposição e paralelamente à católica, principalmente, conforme aponta Mariano (2009), a partir do período de redemocratização na década de 1980.

A articulação política de Igrejas evangélicas tem resultado na formação de considerável força e influência em espaços teoricamente secularizados. Como expressão da organização política religiosa temos as Bancadas Evangélicas, que atuam tanto no Congresso Nacional ${ }^{4}$ como nas Assembleias Estaduais e, em alguns municípios, nas Câmaras Municipais (ORO, 2005). Ocorre que a emergência destes atores e organizações religiosas em diferentes níveis da

\footnotetext{
${ }^{4}$ No Congresso Nacional, apesar de estar há anos se articulando politicamente, a Bancada Evangélica foi registrada somente em 2003, com a criação da Frente Parlamentar Evangélica (FPE). Contudo, somente em 2015 ela foi oficialmente reconhecida, passando a contar com pelo menos um terço da Câmara, na ocasião com 203 membros. Maiores informações disponíveis em:

<https://www.camara.leg.br/internet/deputado/frenteDetalhe.asp?id=53658>. Acesso em: 14 mar. 2019.
} 
esfera política nacional tem se confrontado com o ideal de laicidade, próprio dos estados republicanos modernos do ocidente, assim como com o processo de secularização do espaço público, que visa reservar a presença e atuação religiosa aos ambientes privados.

Sustentados na trajetória católica de estreita ligação com o Estado brasileiro e da aguda aproximação dos evangélicos com a política, estes grupos religiosos têm reconfigurado as relações entre religião e Estado, e traçado novos desafios para pensarmos que tipo de laicidade é construída no país. Atento a este movimento, Giumbelli (2014) indica novas maneiras para se pensar a questão da laicidade, não mais como um modelo teórico estático, engessado, mas que busca compreender como a religião vem se constituindo nos diferentes espaços públicos. Neste sentido, Camurça (2017, p. 859) conclui que “ao invés do que a laicidade deve ser segundo paradigmas jurídicos, constitucionais e programáticos, deve-se contemplar como os atores sociais contextualizados se apropriam destas normas consagradas como 'regime laico' em função dos seus interesses e projetos". Desta forma, a ideia proposta pelos autores seria de buscar entender a laicidade como fruto das distintas relações estabelecidas entre agentes religiosos, Estado e espaço público, considerando assim as questões históricas, sociais, culturais e políticas que cada país e região apresentam e que podem influenciar no entendimento do que se denomina laicidade. No caso brasileiro, a presença religiosa no espaço público tem ocorrido não em oposição à secularização, mas ancorada juridicamente no princípio da laicidade, da liberdade e da pluralidade religiosa, que asseguram sua livre organização e garantem seu direito de manifestação (GIUMBELLI, 2008). Para Mariano (2011, p. 254), "a laicidade do Estado brasileiro tem sido acuada pelo avanço de grupos católicos e evangélicos politicamente organizados e mobilizados para intervir na esfera pública”.

Nas mídias sociais digitais, assim como tem ocorrido em outros âmbitos da esfera pública, a presença religiosa evangélica vem sendo marcada pelo posicionamento moralmente conservador ${ }^{5}$, especialmente no que tange a assuntos ligados à sexualidade, aborto, drogas, defesa da família e direitos humanos. No interior da política institucionalizada, alinhada a postura de restrição de direitos, temos a partir dos anos de 2010 um conservadorismo moral que passa a se acentuar na atuação da FPE, que se coloca como "primado moral" da nação (TADVALD, 2015), e toma como foco de debate a "defesa da família e da moral cristã contra a plataforma dos movimentos feministas e homossexuais" (CUNHA, 2017a, p. 254). Neste

\footnotetext{
${ }^{5}$ Os grupos evangélicos brasileiros têm apresentado uma postura liberal no campo econômico, em defesa do Estado mínimo, e conservadora no campo moral - em defesa da família tradicional e contra pautas reivindicadas por grupos progressistas, como a legalização do aborto, das drogas e a união homossexual.
} 
sentido, Almeida destaca a disputa por moralidade pública, "que no Brasil encontra nas religiões cristãs os principais canais de sacralização da família e da reprodução da vida" (2018, p. 182). Nesta disputa, se tornaram protagonistas deste conservadorismo moral religioso os evangélicos pentecostais, que visam, sobretudo, o controle rígido dos corpos, assim como seus comportamentos e relações.

Temos em meio a estes embates uma disputa entre grupos evangélicos, católicos e laicos para inscrever legalmente seus valores no cenário público. A autora Machado (2012, p. 49) sinaliza que "verifica-se neste início de século uma acirrada disputa de sentidos em torno da vida e da sexualidade humana entre as ideologias de matriz cristã e as de caráter secular, como as dos movimentos feministas e pela diversidade sexual". Surge a partir daí uma motivação das instituições religiosas por terem seus projetos morais reconhecidos na forma de lei, em uma busca tanto por reconhecimento como por audibilidade, em "verdadeiras e importantes lutas simbólicas" (SEGATO, 2006, p. 212). Neste embate entre setores laicos e religiosos, o que está em jogo, segundo apontamentos de Segato (2006), além da prática em si - como aborto e relacionamento entre pessoas do mesmo sexo -, é o reconhecimento legal da nação e demais comunidades morais que a legitimam.

Com base nas discussões realizadas, buscamos analisar nos materiais de campanha de candidatos evangélicos à ALEP a presença de discursos em defesa dos valores cristãos, da defesa do armamento da população e do combate às drogas. Para tanto, juntamente com demais membros do Grupo de Pesquisa Cultura e Relações de Poder, da Universidade Estadual do Paraná, campus de Campo Mourão, acompanhamos durante o período eleitoral de 2018 os candidatos evangélicos identificados como religiosos políticos, ou seja, aqueles que evidenciaram explicitamente sua ligação com a igreja a qual eram vinculados (CARVALHO JUNIOR; ORO, 2017). Neste processo identificamos 45 candidatos (Tabela 1$)^{6}$, e coletamos de suas páginas e perfis da mídia social Facebook seus materiais de campanha que, direta ou indiretamente, apresentaram relação com valores morais e religiosos ${ }^{7}$. A vinculação dos candidatos por denominação ficou dividida entre 18 Igrejas evangélicas, embora parte deles

\footnotetext{
${ }^{6}$ Em uma análise prévia de todos os 766 candidatos registrados para concorrer a uma vaga à ALEP, identificamos um total de 140 candidatos que acionaram a religião, entre eles católicos e pertencentes a religiões de matriz afro. Após uma primeira triagem refinamos nossa busca para os evangélicos, e chegamos ao número de 45 , os quais recorreram de forma mais intensa e explícita aos elementos religiosos em suas campanhas.

${ }^{7}$ Todo o material de campanha aqui analisado foi coletado de páginas e perfis dos candidatos no Facebook, sendo que o acervo está sob responsabilidade do Grupo de Pesquisa Cultura e Relações de Poder, da Universidade Estadual do Paraná, campus de Campo Mourão.
} 
não tenham apresentado ligação direta e exclusiva a uma denominação religiosa. Contudo, em seus materiais constavam conteúdos com menção a Deus, a passagens bíblicas e pautas morais, ou então, como ocorreu com alguns candidatos que utilizaram o título de pastor em seu nome de urna, notamos o trânsito dos mesmos em celebrações de diferentes igrejas, mas sem uma que se mostrasse como a principal. Vale ressaltar que dos 45 candidatos que acompanhamos, nem todos apresentaram materiais ligados à temática de nosso interesse, sendo que, na presente investigação, trabalhamos com 12 candidatos que tiveram publicações relacionadas ao objetivo da nossa pesquisa.

Tabela 1: Candidatos evangélicos que acionaram elementos religiosos durante a campanha eleitoral para a ALEP em 2018

\begin{tabular}{|c|c|c|c|c|}
\hline Nome Urna & Partido & Denominação & Votação & Situação \\
\hline Wagner Vivian & PRTB & Igreja Adventista do Sétimo Dia & 569 & Suplente \\
\hline Adalmo Alves & PRTB & Igreja Assembleia de Deus & 1.585 & Suplente \\
\hline Apóstolo Gilmar Carvalho & PSL & Igreja Assembleia de Deus & 619 & Suplente \\
\hline Bill Pastéis & PSL & Igreja Assembleia de Deus & 3.596 & Suplente \\
\hline Cantora Mara Lima & PSC & Igreja Assembleia de Deus & 33.866 & Suplente \\
\hline Carla Pimentel & PSC & Igreja Assembleia de Deus & 8.495 & Suplente \\
\hline Damasceno Junior & DC & Igreja Assembleia de Deus & 937 & Suplente \\
\hline Denilson Caleran & PDT & Igreja Assembleia de Deus & 3.713 & Suplente \\
\hline Misael Pereira Junior & PSC & Igreja Assembleia de Deus & 12.195 & Suplente \\
\hline Noemia Rocha & MDB & Igreja Assembleia de Deus & 10.442 & Suplente \\
\hline Oziel Rodrigues & PPS & Igreja Assembleia de Deus & 1.020 & Suplente \\
\hline Pastor Luciano Baruk & Podemos & Igreja Assembleia de Deus & 241 & Suplente \\
\hline Pr Luiz Alsione / O Mascara & PSC & Igreja Assembleia de Deus & 5.210 & Suplente \\
\hline Pastor Sandro Martins & $\mathrm{PV}$ & Igreja Batista & 5.148 & Suplente \\
\hline Professor Luiz Arnaldo & $\overline{P R}$ & Igreja Batista & 1.675 & Suplente \\
\hline Karl Dietz & $\overline{P R}$ & Igreja Comunhão Cristã Abba & 3.650 & Suplente \\
\hline Pastora Tatiane Galvão & PRB & $\begin{array}{c}\text { Igreja Comunidade Evangélica Firme } \\
\text { na Rocha }\end{array}$ & 285 & Suplente \\
\hline Claudia Pereira & PSC & Igreja Congregação Cristã no Brasil & 22.428 & Suplente \\
\hline Gilson De Souza & PSC & Igreja do Evangelho Quadrangular & 46.116 & Reeleito \\
\hline Juninho Pemac & PV & Igreja do Evangelho Quadrangular & 2.692 & Suplente \\
\hline Criméria & $\begin{array}{l}\text { PRTB } \\
\end{array}$ & Igreja Evangélica Sonhos de Deus & 59 & Suplente \\
\hline Dra. Andreza Albuquerque & PSD & Igreja Internacional da Graça de Deus & 11.166 & Suplente \\
\hline Pastor João Dos Anjos & PRTB & Igreja Irmãos Menonitas & 657 & Suplente \\
\hline Missionário Ricardo Arruda & PSL & Igreja Mundial do Poder de Deus & 27.574 & Reeleito \\
\hline Ezequias Barros & PRP & Igreja O Brasil Para Cristo & 12.714 & Suplente \\
\hline Pastor Alessio Violato & PSL & Igreja Pentecostal Só Jesus é a Verdade & 2.230 & Suplente \\
\hline Gabriel Antunes & PMN & Igreja Presbiteriana & 1.646 & Suplente \\
\hline Ed Claudio Cruz - Claudinho & PSL & Igreja Só O Senhor é Deus & 1.115 & Suplente \\
\hline Alexandre Amaro & PRB & Igreja Universal do Reino de Deus & 49.565 & Eleito \\
\hline Samuel Pinheiro & PRB & Igreja Vida Plena & 5.885 & Suplente \\
\hline Pastor Adão & PRTB & Igreja Evangélica Renascer & 301 & Suplente \\
\hline Delegado Jacovos & PR & Não identificado & 61.310 & Eleito \\
\hline Elizeu Liberato & PR & Não identificado & 7.819 & Suplente \\
\hline Galo & Podemos & Não identificado & 26.210 & Eleito \\
\hline
\end{tabular}




\begin{tabular}{lclcc} 
Joao Geraldo Barros & PSC & Não identificado & 4.141 & Suplente \\
\hline João Mendonca & MDB & Não identificado & 3.832 & Suplente \\
\hline Marco Zilio & Solidariedade & Não identificado & 1.194 & Suplente \\
\hline Marquinhos Roque & PODE & Não identificado & 13.051 & Suplente \\
\hline Pastor Silvio Toshio & PRTB & Não identificado & 2.985 & Suplente \\
\hline Pastor Wellington Dias & PRTB & Não identificado & 109 & Suplente \\
\hline Rosângela Silveira & PSC & Não identificado & 632 & Suplente \\
\hline Soldado Fruet & PROS & Não identificado & 35.231 & Eleito \\
\hline Vandeli Lima & PP & Não identificado & 356 & Suplente \\
\hline Vava Locutor/Fisioterapeuta & PRP & Não identificado & 397 & Suplente \\
\hline Ze Luiz & PSD & Não identificado & 1.059 & Suplente \\
\hline & & Fonte: Dados da pesquisa. & &
\end{tabular}

Em meio a outras mídias sociais digitais, optamos pelo Facebook, por conta do grande volume de deputados que a utilizaram como instrumento de suas campanhas, além do alto número de usuários que apresenta em solo brasileiro ${ }^{8}$. Além disso, o baixo custo, na maioria das vezes custo zero, e facilidade para publicar materiais e conteúdos diversos, contribuiu para ampliar a utilização do Facebook como um dos principais instrumentos de campanha acionados pelos candidatos à ALEP. Entre os materiais identificamos vídeos, fotos, textos, jingles, lives, "memes", entre outras publicações, tanto de produção dos candidatos como compartilhamentos de outros perfis, páginas e demais sites de notícias. Coletamos os materiais publicados no Facebook entre os dias 20 de julho de 2018 e 10 de outubro de 2018. Após a coleta fizemos a organização e tabulação dos materiais, buscando os conteúdos em que constavam as temáticas de nosso interesse.

Para a presente investigação dividimos o texto em dois eixos: no primeiro procuramos verificar como o discurso em defesa da moralidade cristã na política esteve presente nas campanhas; na sequência analisamos os materiais que se mostraram relacionados à defesa do armamento da população e do combate às drogas.

\section{"Para os princípios bíblicos serem defendidos"}

Presente em várias das campanhas analisadas, a fala dos candidatos em relação à honestidade e moralidade da qual os cristãos são portadores - ao menos segundo eles próprios - se mostrou recorrente. Relacionado ao tema da defesa dos valores cristãos na política, destacamos em nossa análise trechos do conteúdo de sete campanhas eleitorais. Para justificar

\footnotetext{
${ }^{8}$ O Brasil é atualmente é um dos 5 países no mundo com maior número de usuários do Facebook, com aproximadamente 127 milhões de contas ativas. Disponível em: <https://www1.folha.uol.com.br/tec/2018/07/facebook-chega-a-127-milhoes-de-usuarios-mensais-nobrasil.shtml>. Acesso em: 19 mar. 2019.
} 
a participação de religiosos na política institucionalizada, os discursos dos candidatos são, em partes, embasados em princípios bíblicos. Como exemplo, temos o trecho retirado de Provérbios 29:2 - uma passagem recorrente entre as falas e publicações dos pesquisados - que diz o seguinte: "quando os justos governam, alegra-se o povo, mas quando o ímpio domina, o povo geme" (BÍBLIA SAGRADA, 2013). Nestes casos, buscam apresentar as pessoas vinculadas à igreja como fonte de moralidade e honestidade, como sendo elas os "justos" de que trata o excerto do livro sagrado para os cristãos. Neste sentido, em defesa dos ensinos bíblicos, a candidata Cantora Mara Lima (Partido Social Cristão - Assembleia de Deus) coloca como uma de suas pautas de campanha o seguinte: "para os princípios bíblicos serem defendidos", se comprometendo a salvaguardar a bíblia como um livro de regramento social, o qual deve ser preservado.

Buscando demonstrar a importância de estreitar as relações entre religião e política, a candidata Carla Pimentel (Partido Social Cristão - Assembleia de Deus) publicou em seu perfil uma imagem com uma frase de Charles Spurgeon - antigo pregador da Igreja Batista do século XIX - que diz o seguinte: "só os tolos acreditam que política e religião não se discutem. Por isso os ladrões permanecem no poder e os falsos profetas continuam a pregar". O trecho trata como "tolos" aqueles que pensam que tal relação não deve existir, e afirma que este afastamento seria uma das causas da corrupção política. Sendo assim, a presença religiosa na política seria, segundo os candidatos, necessária para que se promova o combate à corrupção no país, em razão dos inúmeros casos desvelados na política brasileira nas últimas décadas, mesmo que em várias delas parlamentares declaradamente religiosos tenham sido acusados e condenados 9 . Desta forma, em uma tentativa de sistematizar o voto evangélico, a ideia de que "irmão vota em irmão", que se tornou conhecida ainda na década de 1980 com a entrada evangélica na política do país de forma articulada (MARIANO, 2009; PRANDI; SANTOS, 2017), se fez presente nas campanhas estaduais paranaenses de 2018, sendo apresentada de forma declarada no material do candidato Eliseu Liberato (Partido da República - Igreja não identificada), ao

\footnotetext{
${ }^{9}$ Como exemplo, temos o caso do ex-presidente da Câmara dos deputados federais, Eduardo Cunha, membro e um dos representantes da Assembleia de Deus no Congresso e filiado ao MDB, o qual foi preso em 2016 e condenado por corrupção, lavagem de dinheiro e evasão de divisas pela operação Lava Jato. Disponível em: <https://www1.folha.uol.com.br/poder/2018/06/juiz-federal-condena-eduardo-cunha-a-24-anos-de-prisao-pordesvios-na-caixa.shtml>. Acesso em: 15 fev. 2019.

No Estado do Paraná, temos o caso do ex-deputado estadual Pastor Edson Prackzyk, ex-representante da Igreja Universal do Reino de Deus (IURD) na ALEP, filiado ao PRB, também envolvido em denúncias de casos de corrupção. O ex-deputado foi acusado de empregar funcionários fantasmas entre os anos de 2000 e 2004, entre eles parentes e pastores da própria IURD.
} 
compartilhar um vídeo do Jornalista Ricardo Azevedo que afirmou que "cristão vota em cristão", e defende a mobilização dos cristãos para colocar seus pares na política.

Ainda tratando da imbricação entre religião e política, a candidata Cantora Mara Lima publicou um vídeo de entrevista do Pastor Silas Malafaia, em que o mesmo afirma que "o estado é laico, mas não é laicista. [...] Como é que eu que sou cristão não posso ser cristão na política". Este tipo de argumento é também utilizado por parlamentares no Congresso Nacional para garantir o direito de defesa dos valores dos grupos evangélicos no qual representam (MACHADO, 2017). Com isso, é possível notar novamente um deslocamento e alinhamento destes discursos para as campanhas eleitorais, que é justificado juridicamente pelo princípio constitucional de liberdade religiosa (MONTERO, 2006).

Nesta "batalha" contra a corrupção e a favor da moralidade cristã, além dos grupos minoritários, como feministas e LGBT`s, que buscam romper com a barreira da família tradicional, o Partido dos Trabalhadores (PT) é também considerado pelos grupos conservadores um inimigo a ser repelido. O referido partido é considerado uma das expressões do comunismo no Brasil, tanto por suas políticas sociais voltadas para as classes inferiores, como "por ter aberto o caminho para a ampliação de direitos das mulheres e LGBTIs quando assumiu o poder executivo nacional em 2003" (CUNHA, 2017b, p. 255), tendo possibilitado a ascensão de grupos até então marginalizados, e que passaram a ecoar suas vozes no âmbito público. A partir de então, a atuação dos governos petistas gerou uma mescla de antipetismo e anticomunismo, muitas vezes tratadas como sendo a mesma coisa (MIGUEL, 2016). Além do PT, os demais partidos considerados pela extrema direita como pertencentes a esquerda ${ }^{10}$ política do país foram alvos de ataques, sendo acusados por desvirtuarem valores ligados a doutrinas cristãs. A tentativa destes candidatos foi de reforçar a ideia construída há décadas e apoiada por várias Igrejas evangélicas, em especial a partir do período militar iniciado em 1964 no Brasil (MARIANO, 2009), de que o comunismo seria uma "ameaça" à sociedade, e que coloca em risco os valores cristãos e os moldes familiares tradicionais, sendo assim um mal a ser combatido.

\footnotetext{
${ }^{10}$ No Brasil, atualmente, os grupos evangélicos brasileiros têm apresentado uma postura liberal no campo econômico, e conservadora no campo moral, com um posicionamento que se mostra próximo do espectro políticoideológico considerado de "direita", enquanto o polo da "esquerda" trata de interesses investidos em setores de caráter mais "cultural" ou "social", ancorados, entre outros pressupostos, na defesa da diminuição das desigualdades econômicas e na maior intervenção do Estado na sociedade (TAROUCO; MADEIRA, 2013).
} 


\section{relegens thrésketa}

Seguindo durante as campanhas estas premissas, tivemos no período eleitoral por parte de alguns candidatos uma busca por demonizar a noção de comunismo, e de afastar os eleitores cristãos, em especial os evangélicos, de votarem em candidatos ligados a esta expressão política, como podemos perceber na Figura 1. Este processo, segundo Ab’Sáber (2018), embora exista há décadas no Brasil, foi acionado com intensidade novamente durante os últimos anos do governo petista, em que a oposição ao então governo buscou forjar sob o PT a imagem do mal representado pelo comunismo. Nesta guerra forjada, alguns grupos evangélicos estão inseridos como combatentes, sendo preciso escolher entre ser cristão ou ser de esquerda. Procurando reafirmar esta oposição, o Pastor Silas Malafaia, em vídeo publicado pelo candidato Oziel Rodrigues (Igreja Assembleia de Deus - Partido Popular Socialista) em sua página no Facebook, afirma que "é esquerda ou é cristão, os dois não dá", incentivando o voto em partidos políticos da direita e seus representantes. Ou seja, da forma como a esquerda é apresentada, suas doutrinas ideológicas seriam incompatíveis com os preceitos cristãos.

Figura 1: Comparação dos candidatos entre eleitores da direita e da esquerda

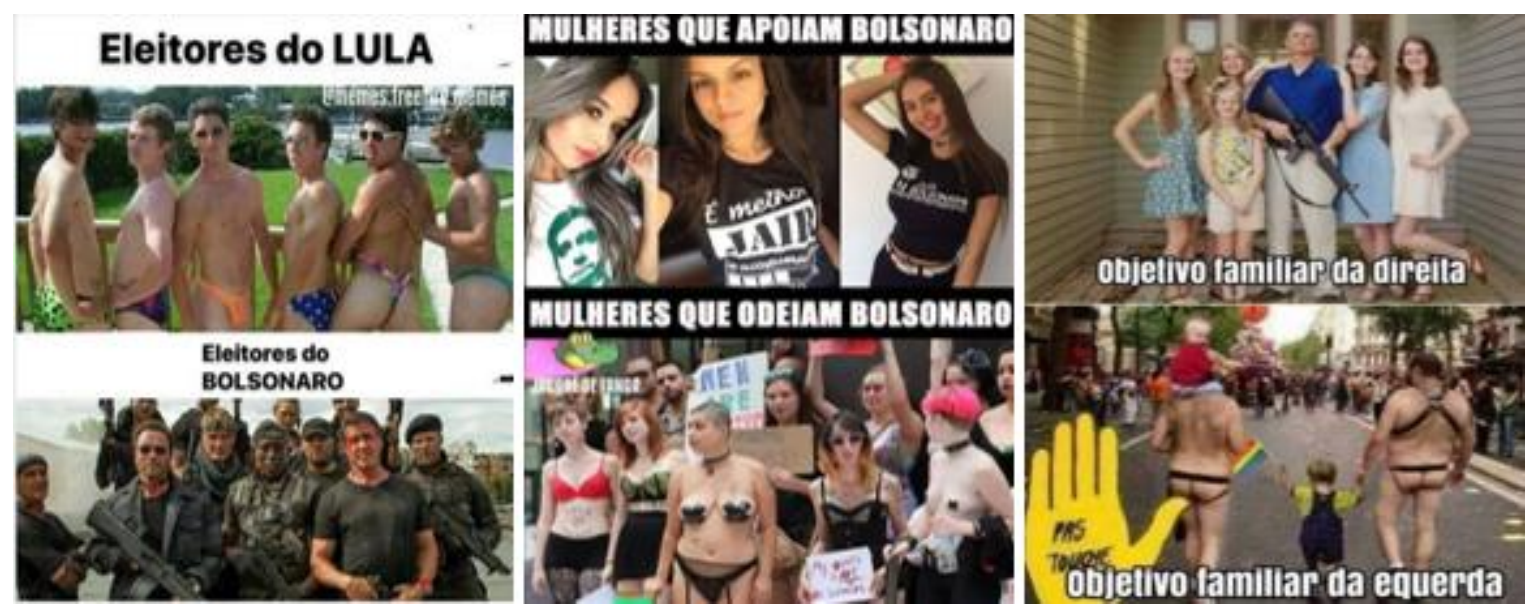

Fonte: Acervo do Grupo de Pesquisa Cultura e Relações de Poder.

Esta forma de entender a esquerda é reforçada por afirmações um tanto agressivas, se pensarmos a partir do ponto de vista religioso cristão, como a apresentada pelo candidato Pastor Alessio Violato (Partido Social Liberal - Igreja Pentecostal Só Jesus é a Verdade), que recorre ao posicionamento de uma figura conhecida da Igreja Católica, Padre Cícero, para ressaltar algo que aparentemente acredita: as relações estreitas entre comunismo e o diabo. Na publicação, o texto atribuído ao religioso católico diz que "o comunismo foi fundado pelo demônio. Satanás é seu chefe e a disseminação de sua doutrina é a guerra contra Deus". Para combater este 
suposto mal colocado como responsável por todas as mazelas pelas quais passa o país, a solução para os problemas causados por este sistema, conforme proposto em publicação do candidato Pastor Luciano Baruk (Podemos - Igreja Assembleia de Deus), seria eleger o maior número possível de cristãos. Contudo, ao realizar ataques ao sistema comunista que supostamente estaria agindo no país, se desconsidera a conjuntura econômica e social vigente há anos no Brasil que não está ligada a ações que tem por base teorias comunistas (AB'SÁBER, 2018). Aqui, mais uma vez, os candidatos evangélicos são retratados como depósito de hombridade e ordem, apresentados como a "salvação" do país.

Em uma destas investidas contra a esquerda, o candidato Missionário Ricardo Arruda (Partido Social Liberal - Igreja Mundial do Poder de Deus) afirmou em uma de suas lives que “esses partidos ligados à esquerda comunista fazem tudo contrário ao que é correto, ao que a palavra de Deus diz, ao que as famílias pregam”. Notamos com isso uma generalização radical das posições assumidas pelos partidos considerados de esquerda por estes grupos, que em sua maioria apoia as lutas por causas progressistas e pela ampliação de direitos para as camadas populares, mas que na prática nem sempre seguem como norteadora as teorias comunistas, e em alguns casos, ao se tratar da área econômica por exemplo, se aproximam das políticas neoliberais.

Ao buscarem reforçar esta interpretação da esquerda, em especial do que acreditam ser o comunismo, alguns candidatos apresentaram eleitores e demais adversários, ligados a este espectro político, como pervertidos, desvirtuados e imorais. Em especial nas eleições de 2018, devido a intensa polarização política, os eleitores que se colocavam contra o então candidato à presidência Jair Bolsonaro (PSL), considerado o representante da extrema direita conservadora brasileira, foram, em algumas situações, taxados como simpatizantes, ou mesmo defensores dos ideais da esquerda, em especial aqueles que se declaravam apoiadores do candidato à presidência pelo PT, inicialmente Lula e oficialmente Fernando Haddad.

Como demonstram as publicações da Figura 1, as montagens tratam de comparações entre eleitores ligados à direita - defendida pelos candidatos -, que seguem o modelo patriarcal heteronormativo de comportamento e de família (SANTOS, 2018), e eleitores que estariam vinculados à esquerda, os quais fogem das regras socialmente aceitas, buscam quebrar padrões de comportamento estabelecidos para homens e mulheres, e incorporar ao convívio social novas formas de relacionamentos, considerados, por isso, subversivos e uma ameaça à ordem vigente. Neste contexto eleitoral, a intenção dos candidatos era coibir os eleitores a votar em candidatos 
da esquerda, utilizando mais uma vez a representatividade assumida pela figura do presidenciável Jair Bolsonaro como oposição desta ala política.

Em uma das imagens da Figura 1, a questão levantada são os objetivos da direita e esquerda em relação à família, as quais são representadas por meio de modelos familiares opostos: a família de direita seguindo a estrutura tradicional patriarcal - com o pai em primeiro plano, ladeado por esposa e filhas, e a da esquerda mostrando uma união homoafetiva entre dois homens - claramente não tolerada pelos candidatos que realizaram as publicações por não estarem, segundo eles, de acordo com os desígnios de Deus. Ao tratar de "objetivo familiar", a postagem tenciona erroneamente que há um projeto de família da esquerda que visa acabar com relações heterossexuais, quando, na verdade, o que se propões são garantias de liberdade e direitos individuais (REIS; EGGERT, 2017).

Nestas postagens, assim como demais formas de posicionamento dos candidatos analisados, não são discutidas as garantias dos sujeitos para expressarem sua orientação sexual publicamente ou ter sua união reconhecida legalmente, muito menos dos inúmeros casos de violência física e simbólica que ocorrem no Brasil todos os dias, causadas pelo machismo e preconceitos em relação à orientação sexual. Tanto nas campanhas como em outros âmbitos políticos, como no Congresso Nacional por parte de grupos conservadores (MACHADO, 2017), a preservação da família tradicional parece estar acima da violência e das inúmeras mortes ocasionadas pela intolerância ligada às diferenças de gênero sexual. A família estaria no centro da moralidade requerida pelos candidatos, sendo eles próprios seus representantes e "guardiões".

\section{Defesa do armamento e combate às drogas}

Legalização e descriminalização do uso de armas e drogas por parte da população são assuntos que há décadas têm gerado acaloradas discussões públicas a respeito de sua regulamentação. Durante as campanhas eleitorais paranaenses de 2018, contudo, estes assuntos não foram amplamente explorados pelos candidatos evangélicos, sendo que apenas 4 pleiteantes a uma vaga à ALEP abordaram diretamente estes temas em suas publicações, os quais apresentamos na sequência.

No que se refere ao tema do armamento da população, temos um elemento notável na Figura 1, apresentada no eixo anterior: a presença de uma arma nas mãos do que os candidatos consideram "cidadãos de bem", os quais as utilizam para garantir a ordem social, o combate ao 
crime e a proteção de suas famílias. Respaldados por estes argumentos, alguns candidatos expressaram suas posições em defesa do direito dos cidadãos em andarem armados como forma de combater a criminalidade. O candidato Missionário Ricardo Arruda (Figura 2) se coloca contra o estatuto do desarmamento, aprovado em forma de lei em 2003, e ressalta que tal ação apenas mantém o dito cidadão de bem e as famílias desarmados, desprotegidos, enquanto os bandidos continuam armados. O mesmo candidato defende o fim da idade penal, e não apenas sua redução. Para ele, qualquer pessoa, independente da faixa etária, deve responder criminalmente pelos seus atos. Estas pautas em questão colocam o armamento dos civis, bem como sua prisão independentemente da idade, como uma possível solução para o problema da violência do país, mas não aborda, por exemplo, as péssimas condições de vida em que vive parte da população brasileira, ou demais motivos que possam levar as pessoas a cometerem crimes, ou seja, não tratam das causas reais do problema.

Figura 2: Em defesa do direito de andar armado

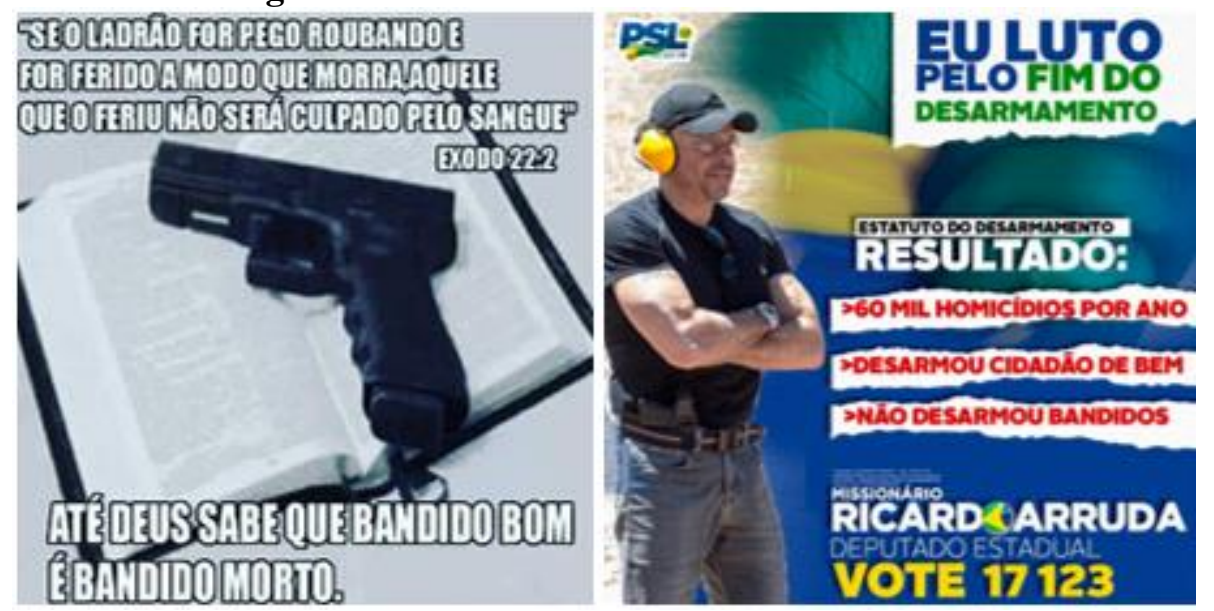

Fonte: Acervo do Grupo de Pesquisa Cultura e Relações de Poder.

Ocorre que esta busca pela manutenção da ordem social, não visa a causa do problema da criminalidade, apenas um duvidoso combate por meio do uso da própria violência, tão rechaçada pelos cristãos. Destarte, utilizando uma passagem bíblica e a imagem de uma arma sob a mesma (Figura 2), Soldado Fruet (PROS - Denominação religiosa não identificada) defende, além do armamento da população, o direito de matar criminosos, e, relembrando a conhecida frase dos defensores da pena de morte, que "bandido bom é bandido morto", destaca que "até Deus sabe que bandido bom é bandido morto". Em consonância com o candidato Soldado Fruet, Ed Claudio Cruz compartilhou um vídeo em sua linha do tempo onde o então presidenciável Jair Bolsonaro declara em entrevista ao programa Roda Viva que dará liberdade 
para a polícia matar bandidos em caso de combate. Aqui, nota-se que há uma moralidade seletiva, que não se aplica a bandidos, assim como o $5^{\circ}$ mandamento da lei de Deus, que diz: “não matarás” (BIBLIA SAGRADA, 2013)ำ, acaba por ser descartado.

A defesa em questão é uma expressão do movimento fundamentalista religioso que despontou nas últimas décadas no Brasil, em partes ocasionado pelo "medo e a ansiedade diante das ameaças diversificadas que pesam sobre o futuro do planeta, mas também a insegurança face à carência de horizontes e à perda de sentido da existência" (TEIXEIRA, 2007, p. 10). Com isso, conforme destaca Hervieu-Léger (2015), nota-se uma perca de confiança nas instituições tradicionais, e um processo de individualização e autonomia pessoal, que vem se tornando característica das sociedades modernas e transformado as relações entre sujeito e religião. Neste processo, interpretações próprias de trechos bíblicos - literalistas e estreitas (TEIXEIRA, 2007, p. 16) -, principalmente do antigo testamento, como o apresentado, se tornam cada vez mais comuns, e são lidos de forma descontextualizada do período histórico e do próprio texto maior onde está inserido, com o intuito de destacar apenas o que for de interesse, tornando-se base para discursos e ações conservadoras e violentas.

Também relacionado ao ideal de preservação da família, o tema da descriminalização das drogas está entre as principais pautas que vão contra valores e crenças de cristãos evangélicos conservadores, assunto alvo de polêmicos embates tanto no meio político como no religioso. Tais discussões por parte de fundamentalistas religiosos cresceram exponencialmente no Brasil no âmbito público a partir do governo de Lula (PT) (MACHADO, 2012), assim como outras pautas de cunho progressista passaram a ganhar espaço no âmbito político - tendo se agudizado durante o mandato de Dilma Roussef (MACHADO, 2017b). Estas discussões se ampliaram e estenderam-se às campanhas eleitorais de 2018, sendo que os candidatos evangélicos analisados na presente pesquisa, de forma geral, apresentaram posturas rígidas em relação à legalização da comercialização e consumo de drogas.

O tema da legalização das drogas esteve presente em algumas pautas de campanha de alguns candidatos, entendida novamente como uma ameaça às famílias. O debate sobre a legalização das drogas é recorrente no meio público brasileiro (SANTOS, 2018; BARROS; MARTA, 2011), em especial sobre o uso da maconha ${ }^{12}$, e tanto a Igreja Católica como, em sua

\footnotetext{
${ }^{11}$ Livro de Êxodo 20:13.

12 Ocorre anualmente em diversas cidades brasileiras, assim como em outros países, a chamada Marcha da Maconha, em que manifestantes se reúnem para reivindicar a flexibilização das leis que regulamentam o uso da erva de forma recreativa bem como a descriminalização do seu comércio (BARROS; MARTA, 2011).
} 


\section{relegens th̆résketa}

maioria, as evangélicas se posicionam contrariamente à legalização do consumo e comercialização de entorpecentes. Conforme pesquisa realizada por Prandi e Santos (2017), há um certo consenso por parte da população brasileira, em que aproximadamente $82 \%$ das pessoas concordam com o que pregam as igrejas em relação à proibição das drogas. Além do discurso dos líderes religiosos contra o consumo de drogas, o trabalho social com dependentes químicos realizado por diversas igrejas no Brasil corrobora com seu posicionamento e combate à esta suposta ameaça. Neste sentido, alguns candidatos evangélicos analisados apresentaram propostas e pautas de campanha de combate às drogas (Figura 3), ou então, exploraram em suas campanhas o papel das igrejas no trabalho de recuperação de usuários de drogas.

Como exemplo, tivemos a candidata Noemia Rocha, membra da Assembleia de Deus e filiada ao Movimento Democrático Brasileiro (MDB), que gravou vídeos de sua visita à Comunidade Terapêutica Hermon para pedir votos e falar sobre a importância do projeto. A Comunidade Hermon atua na recuperação de dependentes químicos na região metropolitana de Curitiba, em seu site apresenta como um de seus objetivos a prática da espiritualidade sem a imposição de crenças religiosas ${ }^{13}$, embora, durante o vídeo, a candidata Noemia Rocha faça referência a pastores, mas sem citar uma igreja específica. Explorando o trabalho social com usuários de drogas tivemos também o candidato Ed Claudio Cruz (PSL), que dedica parte de seu tempo a um trabalho evangelístico realizado em uma chácara subsidiada pela Igreja Só o Senhor é Deus, que se propõe acolher e reintegrar dependentes químicos na cidade de Campo Mourão, Paraná.

Figura 3: Candidatos contra a legalização das drogas e em apoio ao trabalho das igrejas

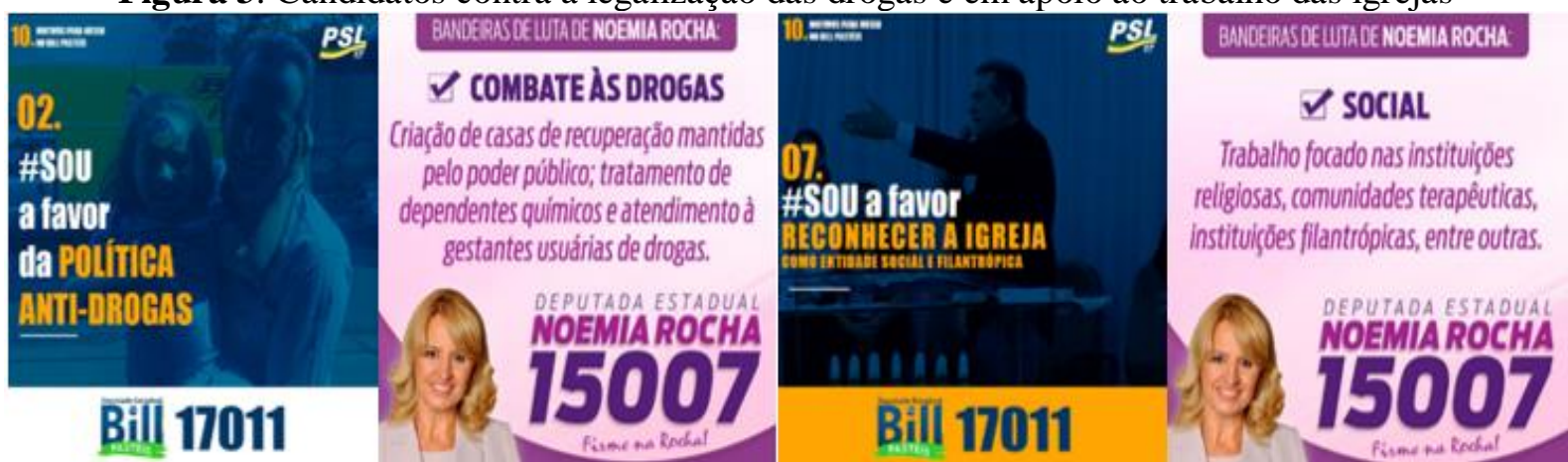

Fonte: Acervo do Grupo de Pesquisa Cultura e Relações de Poder.

13 Objetivos da Comunidade Terapêutica Hermon disponível em: 〈https://comunidadehermon.wordpress.com/〉. Acesso em: 7 mar. 2019. 
Conforme Figura 3, houve por parte dos candidatos a defesa do reconhecimento das igrejas como entidades filantrópicas devido ao seu papel social, as quais passariam assim a receber benefícios fiscais e previdenciários para exercerem suas atividades. A candidata Noemia Rocha publicou um vídeo de uma de suas falas no plenário da câmara municipal de Curitiba, onde é vereadora, em que defende a atuação das instituições religiosas no tratamento e combate às drogas, e afirma que "a comunidade religiosa faz com perfeição a recuperação de jovens da dependência química por ideal. Sem dinheiro, sem apoio do poder público, com muitas dificuldades". Para Mariz, os discursos religiosos sobre seus próprios trabalhos sociais “desempenham papel importante na construção de uma imagem positiva do grupo religioso e na luta por legitimidade no jogo político e por acesso a verbas públicas que financiem seus projetos sociais" (2016, p. 2). A exposição destes trabalhos por parte de membros das igrejas também busca dar visibilidade às instituições religiosas e demonstrar que seu compromisso com a sociedade vai além do campo da espiritualidade - questionamento feito constantemente às igrejas -, e também contribui de forma concreta com práticas sociocaritativas, passando, com isso, a ser alvo de maior interesse público (MARIZ, 2016).

Durante a campanha, o que se percebe é a tentativa dos candidatos em criarem suas representações frente ao eleitorado vinculadas a ações que promovam o bem-estar social e ao trabalho em prol de grupos em situação vulnerável. Contudo, não temos discussões ou pautas voltadas para as causas que levam as pessoas a se tornarem usuárias de drogas, ou mesmo de combate ao tráfico, e tampouco uma melhoria na educação com objetivo de conscientizar as crianças e adolescentes sobre a questão da drogadição. No que tange ao tema do consumo de drogas temos a questão moral acima de questões sociais, como a pobreza e a violência, e de saúde pública, em que se desconsidera as milhares de pessoas que morrem pelo uso excessivo de entorpecentes de forma ilegal.

\section{Considerações finais}

Ao procurar entender, por meio dos materiais de campanha produzidos durante o pleito eleitoral de 2018 no Paraná, as formas de articulação dos candidatos evangélicos em torno do discurso de defesa dos valores cristão como solução para os problemas políticos, do armamento da população civil e do combate às drogas, notamos a recorrência destes temas e como eles foram incorporados à construção de várias campanhas analisadas. Notamos como a família tradicional e os valores cristãos são entendidos pelos religiosos políticos evangélicos que 
pleitearam uma vaga à ALEP como fonte de moralidade e solução para reorganizar a sociedade e se chegar às mudanças e melhorias que, segundo eles, o país precisa. A família estaria, conforme percebido nos materiais, ameaçada pelos anseios de grupos políticos de esquerda, que supostamente desejam desintegrar o modelo de família heteronormativo e banir as religiões do cenário público.

As pautas de campanha aqui estudadas são colocadas como justificativas para que os religiosos políticos sejam eleitos, sendo a relação entre religião e política defendida como fundamental para trazer ao país a "moralidade perdida". A disputa moral travada entre os grupos religiosos e laicos é percebida também nas campanhas, e a tentativa de legitimação do discurso cristão é apresentada em oposição ao que defendem, por exemplo, os movimentos feministas e LGBT's. Para tanto, criam inimigos e, em tom apelativo, se declaram em "guerra espiritual" e como futuros representantes de Deus na Câmara estadual.

Diante do material e análises apresentadas, notamos também que a intenção de descredibilizar os candidatos e eleitores do espectro ideológico da esquerda - os quais, para boa parte dos evangélicos, tem sua representação máxima no PT -, acabou por exacerbar pautas morais e ressaltar uma suposta importância do patriarcado. Por consequência, ocorreu o ocultamento de demais discussões relacionadas à desigualdade social, desemprego, saúde, questões ambientais, entre outras, ficando restrita à ideia de sacralização familiar e defesa da ordem cristã. Algumas questões como o porte de armas, combate ao aborto e o tratamento de usuários de entorpecentes, presentes nas pautas de campanhas, são propostas de medidas paliativas, mas que não discutem as origens dos problemas. Não discutem, por exemplo, as raízes da violência ao tratar do porte de armas, os motivos que levam um jovem a se tornar usuário de drogas, ao propor o incentivo a clínicas de tratamento toxicológico e ao tentar barrar, a todo custo, as possibilidade de sua descriminalização. As análises demonstraram ainda como os candidatos se apropriaram de argumentos religiosos na defesa de suas pautas, invertendo ou distorcendo, muitas vezes, o significado de determinados pontos para que passem a condizer com seus interesses - como foi o caso do uso de trechos bíblicos.

Conforme nos aponta Machado (2012), é preciso refletir sobre os riscos da falta de regulação da participação dos religiosos no campo político, de modo que garanta o acesso mínimo aos direitos humanos e não coloque em risco a democracia do país. Além disso, percebemos que a laicidade estatal se mostra ameaçada pelo avanço religioso sobre a esfera 
pública, que hoje se apresenta distante do ideal republicano que prega a separação entre Estado e religião e deslocamento religioso para o âmbito privado.

O trabalho aqui apresentado não esgota as possibilidades de análise do material coletado, mas apresenta uma amostra de como os religiosos evangélicos estão articulando suas forças e discursos para inscrever na sociedade seus valores e crenças religiosas. Tais ações e narrativas são realizadas mesmo que acabem por alterar o entendimento comum do que é laicidade, que represente o posicionamento apenas de uma parcela da população, e acabe por polarizar ainda mais a sociedade brasileira.

\section{Referências}

AB'SÁBER, T. Crise, alucinose e mentira: o anticomunismo do nada brasileiro. In: ALMEIDA, Ronaldo de; TONIOL, Rodrigo (Orgs.). Conservadorismos, fascismos e fundamentalismos: análises conjunturais. Campinas: Editora da Unicamp, 2018, p. 117-142.

ALMEIDA, R. Deuses do parlamento: os impedimentos de Dilma. In: ALMEIDA, Ronaldo de; TONIOL, Rodrigo (Orgs.). Conservadorismos, fascismos e fundamentalismos: análises conjunturais. Campinas: Editora da Unicamp, 2018, p. 163-193.

BÍBLIA SAGRADA. Várzea Paulista: Casa Publicadora Paulista, 2013.

CAMURÇA, M. A questão da laicidade no Brasil: mosaico de configurações e arena de controvérsias. Horizonte, Belo Horizonte, v. 15, n. 47, p. 855-886, jul./set. 2017.

CARVALHO JUNIOR, E.; ORO, A. Eleições municipais 2016: religião e política nas capitais brasileiras. Debates do NER, Porto Alegre, ano 18, n. 32, p. 15-68, jul./dez. 2017.

CUNHA, M. Política, mídia e religião: o ativismo progressista entre evangélicos brasileiros por meio do Facebook e do Twitter. Comunicação \& Sociedade, São Bernardo do Campo, v. 39, n. 3, p. 217-244, set./dez. 2017a.

CUNHA, M. Construções imaginárias sobre a categoria "gênero" no contexto do conservadorismo político religioso no Brasil dos anos 2010. Perspectiva Teológica, Belo Horizonte, v. 49, n. 2, p. 253-276, maio/ago. 2017 b.

GIUMBELLI, E. A presença do religioso no espaço público: modalidades no Brasil. Religião e Sociedade, Rio de Janeiro, v. 28, n. 2, p. 80-101, 2008.

GIUMBELLI, E. Cultura pública: evangélicos e sua presença na sociedade brasileira. In: GIUMBELLI, E. (Org.). Símbolos religiosos em controvérsias. São Paulo: Terceiro Nome, 2014, p. 189-208.

IBGE. Censo 2010. Rio de Janeiro, 2010. Disponível em: 〈https://censo2010.ibge.gov.br/> . Acesso em: 14 mar. 2019. 
MACHADO, M. Aborto e ativismo religioso nas eleições de 2010. Revista Brasileira de Ciência Política, Brasília, n. 7, p. 25-54, jan./abr. 2012.

MACHADO, M. Pentecostais, sexualidade e família no congresso nacional. Horizontes Antropológicos, Porto Alegre, ano 23, n. 47, p. 351-380, jan./abr. 2017.

MARIANO, R. Pentecostais e política no Brasil: do apolitismo ao ativismo corporativista. In: SANTOS, Hermílio (Org.). Debates pertinentes: para entender a sociedade contemporânea. Porto Alegre: EDIPUCRS, 2009, p. 112-138.

MARIANO, R. Laicidade à brasileira: católicos, pentecostais e laicos em disputa na esfera pública. Civitas, Porto Alegre, v. 11, n. 2, p. 238-258, 2011

MIGUEL, L. Da "doutrinação marxista" à "ideologia de gênero" - Escola Sem Partido e as leis da mordaça no parlamento brasileiro. Direito e Práxis, Rio de Janeiro, v. 7, n. 15, p. 590$621,2016$.

MONTERO, P. Religião, pluralismo e esfera pública no Brasil. Novos Estudos, São Paulo, n. 74, p. 47-65, mar. 2006.

ORO, A. Religião e política no Brasil. Cahiers des Amériques latines, Paris, v. 48, n. 49, p. 204-222, 2005.

PRANDI, R.; SANTOS, R. Quem tem medo da bancada evangélica? Posições sobre moralidade e política no eleitorado brasileiro, no Congresso Nacional e na Frente Parlamentar Evangélica. Tempo Social, São Paulo, v. 29, n. 2, p. 187-214, 2017.

REIS, T.; EGGERT, E. Ideologia de gênero: uma falácia construída sobre os planos de educação brasileiros. Educação \& Sociedade, Campinas, v. 38, n. 138, p. 9-26, jan./mar. 2017.

SANTOS, R. Conservadorismo na Câmara dos Deputados: discursos sobre "ideologia de gênero" e Escola sem Partido entre 2014 e 2018. Teoria e Cultura, Juiz de Fora, v. 13, n. 2, dez. 2018.

SEGATO, R. Alteridade e ética no movimento de expansão dos direitos humanos. Mana, Rio de Janeiro, v. 12, n. 1, p. 207-236, 2006.

TADVALD, M. A reinvenção do conservadorismo: os evangélicos e as eleições federais de 2014. Debates do NER, Porto Alegre, ano 16, n. 27, p. 259-288, jan./jun. 2015.

TAROUCO, G.; MADEIRA, R. Partidos, programas e o debate sobre esquerda e direita no Brasil. Revista de Sociologia e Política, Curitiba, v. 21, n. 45, p. 149-165, mar. 2013.

TEIXEIRA, F. O Pluralismo Religioso e a Ameaça Fundamentalista. Numen: Revista de Estudos e Pesquisa da Religião, Juiz de Fora, v. 10, n. 1 e 2, p. 9-24, 2007. 
RECEBIDO em 21/03/19

APROVADO em 18/07/19 